\title{
Re: Blackface in White Space: Using Admissions to Address Racism in Medical Education
}

J Gen Intern Med 36(4):1117-8

DOI: $10.1007 / \mathrm{s} 11606-021-06606-\mathrm{x}$

(C) Society of General Internal Medicine 2021

$\mathrm{W}$ e read with interest the Perspective by Anderson and colleagues $^{1}$ and applaud their commitment to addressing racism in medical training. However, we write with concern that by focusing on the attitudes of individual medical school applicants, the authors imply that racism is a feature of individuals rather than a system. Medical education requires comprehensive approaches to systemic racism. Racism cannot be dismantled by removing racist individuals, it must be abolished through antiracist policies. We cannot merely pluck out weeds; we must change the soil.

Electing not to admit students with "racist beliefs," which are mutable, misses an opportunity to intervene upon the underlying causes of individual racist attitudes. We provide recommendations for reforming the conditions that make it advantageous to think and act in racist ways:

1. Mitigate bias in the admissions process through blinded applications, structured interviews, and antiracist education. Once applicants meet minimum MCAT and GPA thresholds, committees should reduce bias by blinding applications and structuring interviews around behaviorally anchored questions. ${ }^{2,3}$ Further, committee members should be trained in how structural racism negatively impacts certain applicants' abilities to attain measures of achievement (e.g., shadowing experience) typically expected of admissible candidates. Reducing admissions bias can destabilize sentiments of comfort and superiority that accompany racist beliefs.

2. Deconstruct biological racial essentialism and contextualize health disparities within socio-structural determinants. Medical students should learn about the sociopolitical construction of race and the structural determinants of health so as not to develop notions of certain populations as inherently "diseased." This will prevent the development of racist, heuristic assumptions about the utility of race in clinical decision-making.

Received August 20, 2020

Accepted January 5, 2021

Published online January 27, 2021
3. Eliminate race-adjusted tools from clinical practice. Removing race from tools like estimated glomerular filtration rate (eGFR) will eliminate the benefit of the lightened cognitive load that accompanies racist classifications.

4. Reward health and racial equity work. Appropriate benefits through grant funding for health equity research and individual compensation, particularly for Black, Indigenous, and other people of color (BIPOC) who contribute to efforts to "diversify" White spaces, ${ }^{5}$ will promote an ethics of social responsibility toward racial equity.

5. Divest power from individuals who commit racist acts. Individual racist beliefs and behaviors should not be rewarded with increased political capital but instead be discouraged.

Antiracism must not be performative but transformative - it requires individual and institutional costs. Integrated, antiracist policies can change the soil that encourages the growth of weed-like racist attitudes, promoting a more just climate for all.

Marie V. Plaisime, $M P H^{1}$

Jessica P. Cerdeña, M.Phil ${ }^{2}$

${ }^{1}$ Department of Sociology and Criminology, Howard University, 2300 6th Street NW, Washington, DC 20059, USA

${ }^{2}$ Department of Anthropology, Yale University, 10 Sachem Street, New Haven, CT 06511, USA

Corresponding Author: Marie V. Plaisime, MPH; Department of Sociology and Criminology, Howard University, 2300 6th Street NW, Washington, DC 20059, USA (e-mail: marie.plaisime@bison.howard.edu).

\section{Compliance with Ethical Standards:}

Conflict of Interest: The authors have no conflicts of interest to declare.

\section{REFERENCES}

1. Anderson N, Boatright D, Reisman A. Blackface in White Space: Using Admissions to Address Racism in Medical Education. J Gen Intern Med. Published online July 29, 2020. doi:https://doi.org/10.1007/s11606020-06079-4

2. Jerant A, Fancher T, Fenton JJ, et al. How Medical School Applicant Race, Ethnicity, and Socioeconomic Status Relate to Multiple Mini- 
Interview-Based Admissions Outcomes: Findings From One Medical School. Acad Med 2015;90(12):1667-1674. doi:https://doi.org/10.1097/ ACM.0000000000000766

3. Kreiter CD, Yin $\mathbf{P}$, Solow $\mathbf{C}$, Brennan RL. Investigating the reliability of the medical school admissions interview. Adv Health Sci Educ Theory Pract 2004;9(2):147-159. doi:https://doi.org/10.1023/B:AHSE.0000027464. 22411.0f

4. Roberts D. Fatal Invention: How Science, Politics, and Big Business ReCreate Race in the Twenty-First Century. New Press,; 2011:1 online resource (xii, 388 pages).
5. Lerma V, Hamilton LT, Nielsen $\mathbf{K}$. Racialized Equity Labor, University Appropriation and Student Resistance. Soc Probl 2020;67(2):286-303. doi:https://doi.org/10.1093/socpro/spz011

Publisher's Note: Springer Nature remains neutral with regard to jurisdictional claims in published maps and institutional affiliations. 